\title{
The Impact of Digital Technologies on Procurement Infrastructure and Functions at Industrial Enterprises
}

\author{
Viktor Dubolazov \\ Graduate School of Business and \\ Management \\ Peter the Great St.Petersburg \\ Polytechnic University \\ St.petersburg, Russia \\ dubolazov-va@mail.ru
}

\author{
Zoya Simakova \\ Graduate School of Business and \\ Management \\ Peter the Great St.Petersburg \\ Polytechnic University \\ St.petersburg, Russia \\ simakova@kafedrapik.ru
}

\author{
Iuliia Iusma \\ Graduate School of Business and \\ Management \\ Peter the Great St.Petersburg \\ Polytechnic University \\ St.petersburg, Russia \\ 14371768@kafedrapik.ru
}

\begin{abstract}
This Paper studies the impact of digital technologies on logistics business processes, organizational structure and functions of procurement management and its connection with other management functions at the industrial enterprises. The current trends are to centralize procurement management and to create a single logistics center at enterprises, which combine the management of supply chain: procurement, production and sales (distribution), have been determined based on analysis publications and the study of the experience of implementation integrating automated enterprises control systems and digitalization of logistics. It was concluded that this trend increases the efficiency and effectiveness of management and changes control functions, because most of the calculations and reports are performed by computers, and logistics specialists analyze the calculations, organize the execution of tasks, prepare data to correct or compile new tasks. The digitalization level of logistics processes has shown a significant impact on the organizational structure, functions, methods and information tools. For example, in flexible production systems, computer control commands using cyber-physical devices, the Internet of things, various sensors come into robots, manipulators, CNC machines, automatic warehouses, etc. This Paper examines some of these issues, poses problems that should attract the attention of specialists and expands on the research in this direction.
\end{abstract}

Keywords-procurement management, digital technologies, infrastructure, business processes

\section{INTRODUCTION}

The modern ecosystem is based on the application of a wide number of digital technologies: cyber-physical systems, artificial intelligence, neural networks, the Internet of things, robotics, cloud computing technologies, 3D printing, artificial intelligence and others. These technologies promote the creation of new business models, emergence of digital platform services, digitalization of the movement of tangible and information assets, and the integration of the entire supply chain in the enterprise (supply, production, distribution).

At the World Economic Forum (WEF) "The Future of Jobs" in Davos, German economist Professor Klaus Schwab noted that The Fourth Industrial Revolution is a combination of technologies of the physical, digital and biological world, creating new opportunities and influencing political, social and economic systems [1-3].
According to the Boston Consulting Group [4], nine technologies are transforming industrial production: advanced robotics, additive manufacturing, augmented reality, simulation, horizontal/vertical integration, industrial Internet of Things, cybersecurity, the cloud, Big Data and analytics. New digital industrial technologies, called Industry 4.0, which involve robotic devices, sensors, IT-systems in a single network within the company are being implemented in Germany in the field of production and consumption [5]. According to The McKinsey Global Institute, Industry 4.0 is the digitalization of the production process using sensors that are embedded in almost all stages of the production of products and equipment, cyber-physical systems and the analysis of relevant data [6]. This industry has four components. The first component is data collection and transmission. The second is analytics and intelligent data processing. The third is related to the interaction between man and machine through tactile interfaces. The fourth is a digital transformation into physics. [7-9]

Digitalization is becoming one of the priorities for the development of logistics. In this case, both process and structural changes occur, traditional methods of logistic activity are transformed and optimized, saturated with information flows and inevitably accelerated. Nowadays it is difficult to imagine a logistics system that would successfully performed without the use of IT technologies. Digitalization of logistics is a new global trend. Under these conditions, logistics business processes, logistics infrastructure, including procurement, functions of departments and employees, methods for evaluating and motivating their activities are changing.

\section{MATERIALS AND METHODS}

\section{A. Procurement Management Definition}

Procurement Management is a functional subsystem of logistics, that provides organization with inventory, and is the first step in the supply chain. Procurement, purchasing, and supply management are synonyms of procurement management, which can be found in special literature and in practice. This variety is explained by the evolutionary development of the theory in this area, the complexity and diversity of the economic processes reflected in it.

The main task of procurement management is a complex uninterrupted supply of the organization (production, design, trade, transport, service, etc.) with inventory in the required 
quantity and quality, in the required time frame, with the lowest cost and optimal stocks.

At large enterprises, the nomenclature of goods and materials can consist of several hundred thousand items. Depending on the industry, raw materials, intermediate products and finished components range from twenty to eighty percent of the cost of goods, an average of sixty-five percent of the selling price of products [10]. An effective procurement organization and management system will reduce these costs and is an important premise for sustainable business development.

Procurement management should closely interact with production and distribution logistics, providing coordination of their plans and actions, using current accounting of constant changes up to the real-time mode. Implementing the marketing concept of enterprise management, at first, it is necessary to develop a sales strategy (sales), then production and procurement.

There are many basic functions of procurement management: marketing research of the materials market, including imported ones; receipt requests for materials from departments of the enterprise (for maintenance, administration and other needs); material requirements planning, the preparation of material balance; reconciliation; $\mathrm{ABC}$ and XYZ - analysis of materials; search, analysis and selection of suppliers; formation of orders; receiving commercial offers and quotas; price negotiation and conclusion of contracts with suppliers; budgeting procurement; purchase and delivery of materials; security of supply; operational management of the number and timing of delivery of materials; acceptance and quality control of materials; storage (storage) and issue of materials for production; material accounting in a warehouse and control the level of their stocks; planning (calculation of limits and schedules of distribution of materials to departments of the enterprise), accounting, control and analysis of the consumption of materials in production; analysis and disposal of non-liquidity inventory and poor quality materials; recycling materials

In addition, there are supporting functions that support the basic functions of procurement management: the formation and updating of regulatory and reference information; flow of documents management (preparation of contracts for the supply of materials, processing of primary accounting and financial documentation, preparing reconciliation reports), reporting; operational communication with other departments, etc.

The main directions of procurement in the Procurement 4.0 system in terms of digital technologies are discussed further.

\section{B. Centralization of Procurement Management at Industrial Enterprise}

The issue of procurement management centralization across the company (a group of interrelated enterprises) is one of the key issues in the field of procurement at present. There are various options for the organization of procurement activities at the enterprise. One option is to distribute functions that were considered previously between different functional departments of the enterprise: the production department determines the materials requirement; the economic department defines the procurement budget; management of the organization decides the volume of purchases and the choice of suppliers; other departments are responsible for the storage and transportation of materials, etc. In this case, the procurement department mainly performs the work of supplying the enterprise with materials: concludes contracts with suppliers, organizes their supply, distribution among the departments of the enterprise. Alternatively, a separate department (procurement department) in the structure of the management bodies of the enterprise performs all the functions of the procurement activity at the enterprise. The main directions of procurement in the Procurement 4.0 system in terms of digital technologies are discussed further.

In the 1960s - 1970s. in the world and after the Perestroika in Russia, the corporate structure, which arose under the influence of internationalization and diversification of business, became decentralized. Many companies actively pursued a strategy of regional expansion, opened branches and representative offices, created new geographically dispersed production departments. [11,12] The search for ways of cost savings has become relevant with increasing levels of competition, as well as the attendant crisis phenomena in the global economy, and by achieving centralization in procurement. The use of computer systems, electronic communication systems and the internet in management has greatly contributed to this. In many countries, studies have been conducted on the problem of centralizing procurement $[13,14]$.

The tendency to centralize procurement functions continues to this day: according to the results of a survey of Chief Procurement Officers (CPO) of companies in North America and Western Europe, most respondents chose procurement centralization and rationalization of the supplier portfolio as the two most promising tools for optimizing procurement activities. The centralization of procurement activities in each company (a group of interrelated enterprises) was analyzed in two directions: territorial and functional [9]. The second direction involves the concentration of all functions of procurement logistics in the procurement department, which creates ample opportunities for logistics optimization of procurement [15].

\section{Enterprise Logistics Centre}

The procurement (supply) department should fit into the supply chain "purchase - production - sales». Modern integrated management systems SAP, Oracle, 1C-enterprise provide an opportunity to coordinate and promptly adjust management decisions of procurement, production and sales units in the enterprise scale, taking into account the dynamics of the external and internal environment in real time [16].

The functions of management departments are changed, they are exempt from routine calculations, reporting, etc. Their work focuses on the organization of the executive the tasks received from information systems, the operational interaction of employees of different services. The task of the logistics department of the enterprise is to ensure a high degree of consistency in the management of material flows between the supply, production and sales services $[17,18]$. Under these conditions, it is advisable to raise the issue of creating a logistics center in an enterprise that includes 
purchasing, manufacturing, transport and warehousing departments.

\section{Purchase Consolidation}

The centralization of procurement activities, information systems, the Internet provide substantial assistance in the consolidation of procurement, which is carried out by the procurement organizer in the interests of several customers at the same time. As a rule, this type of procurement is used for interconnected enterprises (for example, in a holding company or concern), for a group of branches of one enterprise, with centralized supply of several enterprises purchasing similar goods and materials through large highperformance logistics centres. The organizer of the procurement may be the main company of the holding or one of its subsidiaries. It is possible to transfer the procurement functions to an outsourcing specialized organization - a professional intermediary.

Contract models are the legal basis for the consolidation of purchases; they imply the transfer of certain functions from one holding member to another. Forms of contracts may be different: on rendering mediation services (agency contract, commission contract), contract agreement, contract of sale.

Consolidation of purchases increases the efficiency of procurement and production by reducing costs while increasing the volume of purchases (discounts from suppliers, reducing the initial (maximum) contract price); reduction of logistics costs associated with procurement procedures (search for suppliers, document management, etc.); reduction of transportation costs (route optimization, higher loading of vehicles, etc.), standardization (increasing applicability) of the range of purchased materials.

\section{E. The Use of Computers and Centralization to Accurate Calculation of Material Requirement}

Various methods are used to determine the strategic materials requirement for the planning period (year, quarter):

1) direct counting method, which is widely used in MRPsystems, based on the production program of the enterprise and the consumption rates of materials for manufactured products, used primarily in industrial enterprises, construction companies, prescription composition of products, for example, the composition of the mixture in the smelting of metal; standard service life and replacement, norms of materials consumption during operation, maintenance, repair of facilities, etc.;

2) statistical forecasting methods that use actual data of past periods: extrapolation of time series of actual data on material consumption (exponential smoothing, average dynamics, moving average method, etc.); multifactor correlation and regression modelling;

3) based on requests from departments.

Automation of calculations using a computer has long been widely used. Improvement is carried out through the integrated automation of logistics, the operational management of the main and auxiliary production. The implementation of integrated automated management systems of enterprises in which information is accumulated on actual data, for example, on the consumption of materials, their stocks, etc. provides usage of statistical methods for determining the materials requirements.

Unfortunately, based on the review of the ERP-systems market in Russia in 2016-2017, performed by «Parus» Corporation, it follows that the management of production activities in mechanical engineering is automated in 5\% of enterprises. This makes it difficult to widely use automated systems that can link production operations with the resources used.

In practice, $\mathrm{ABC}$ - and XYZ-analysis of materials are getting more and more widespread, because information on the nomenclature, quantity and cost of materials in the necessary sections are formed from integrated information systems operating in the enterprise (1C, SAP, etc.).

\section{F. Materials and Suppliers Sourcing}

It is necessary to collect information about the market of materials and suppliers, before choosing a source for purchasing materials. At present, the main sources of such information are:

1) The Internet, which allows you to quickly find the right suppliers and prices for materials;

2) electronic trading platforms (ETP), including the international market; online e-catalogues;

3) company catalogues and price lists.

The e-commerce market in recent years has been actively developing, primarily in B2B markets, which can be classified into buyers-created ETPs, which are mainly organized to minimize delivery costs; sellers - to expand customer base and increase sales; third party: industry - for enterprises of the same industry and the most common diversified - regardless of industry. A powerful system has been created that ensures customer interaction with suppliers and participants through electronic communication channels, as well as conducting procurement procedures in electronic form using the Internet.

There are Big Data technologies based on open economic databases for markets research, especially international. Big Data is a series of approaches, tools and methods for processing structured and unstructured data of huge volumes and considerable diversity for obtaining useful and humanreadable results [19]. Internet websites, for example: The World Bank, Atlas Media, Nation Master, International Monetary Fund, UN, Data Market, etc., are sources from which it is possible to obtain large amounts of data and create a forecast based on them using various programming languages.

At the stage of choosing suppliers, as well as any other partners, it is necessary to check their legal status, financial position and business reputation. Problem partners can cause losses in business and attract close attention of tax authorities. In the Russian Federation, numerous sources of business information have been formed that allow you to check the partner and its manager for a good reputation. The Federal Tax Service of Russia - the service "Business risks: check yourself and your counterparty" www.nalog.ru/; www.gks.ru, www.gmcgks.ru; - financial statements (balance sheet and statement of financial results) according to Rosstat; The Unified Federal Register of Information on 
the Facts of the Activities of Legal Entities and many others are important and quite effective sources of official information and statistics.

There are many sources with Big Data that can be used for the research market of materials, search and selection of suppliers. It is important to find ways to work with them. The following methods and analysis techniques are presented in the report of the consulting firm McKinsey \& Companies that apply to Big Data [20]: Data Mining class methods, crowdsourcing, data mixing and integration, machine learning, ensemble learning, neural networks, pattern recognition, simulation modeling, statistical analysis, visualization of analytical data [21]. However, the development of specific methods and their practical implementation is a complex process, this was shown by our work on the creation and implementation of the methodology for studying international markets for an innovative product based on Big Data using neural networks [22].

\section{G. Negotiations with Suppliers}

Negotiations with suppliers are an important, responsible, least formalized and controlled stage of procurement logistics. The following factors determine the success of the negotiations: the level of competition in the market for materials; material profitability; supplier relationships (history, partnership); share of the company's purchases in the supplier's turnover; the professionalism of the purchaser. The centralization of procurement logistics in the company and the information equipment of the negotiators undoubtedly contribute to the success in the negotiations. At present, they can connect to the Internet, Consultant Plus, Garant and other information and legal systems at any time, to the information system of their company, and talk with their managers using smartphones and laptops.

\section{H. Operational Management of Materials Supply}

Planning, operational accounting, control, analysis and regulation of the quantity and timing of delivery of materials to the horizon of current planning are the processes of operational management of the supply of materials. Traditional operational management systems "to order" (in single and small-scale production), "to stock" with a fixed size or rhythm of the delivery schedule (in serial and mass production) are widely used. New systems for Russia are actively being introduced: MRP (material requirements planning), JIT (just in time), VMI (vendor managed inventory), LP (lean production), etc. Digital technologies are used for transmitting and processing information and are aimed at improving the efficiency of calculations, optimization of schedules, reduction of stocks of materials in transit, in warehouses and workplaces, adaptation to changes in the external and internal environment. These issues are widely represented in publications, including ours [16]

Specialists pay attention to the problems of transport and warehouse logistics, including the use of digital technologies in them.

From the standpoint of logistics management, it is necessary to identify some problems. In 2016 and 2017, in the North-West Federal District, the volume of export-import operations, transport and forwarding services plummeted. As a result, many transport companies, especially small ones, ceased to exist, the integration of other companies through mergers and acquisitions occurred.

Consolidated carriages, ridesharing and carpooling began to be used more widely - sharing a vehicle with the help of online search services for travel companions; collaboration the use of free transport of one company to another, in which transport is not enough

Internet of Things (IoT) provides great opportunities in procurement management. IoT allows connected devices to "communicate" with each other within an Internet infrastructure without human intervention. IoT, along with cloud-based GPS, allows to track individual items using radio frequency identification (RFID) chips, which transmit information about an object like identification, location, temperature, pressure and humidity (for example, in a container), etc. Due to this, the goods will not be lost or damaged [23].

\section{RESULTS}

The main features of the modern stage of digitalization of the economy and the application of digital technologies at industrial enterprises in logistics are formulated in the Paper. The need for complex digitalization and automation of the entire supply chain at an enterprise, including supply (procurement logistics) - production (production logistics) sales (distribution logistics) and associated logistics processes (transport, storage, auxiliary and servicing), was emphasized. It was concluded that in terms of the functioning of an integrated automated enterprise management system and the digitalization of logistics processes, it is necessary to centralize logistics management at the enterprise in a single logistics center, including the purchasing department, production department, sales department and others, which will increase the consistency and controllability of their activities, efficiency in making management decisions. It is concluded that the expediency and efficiency of consolidation of purchases in a group of interrelated enterprises. The functions of procurement logistics at an industrial enterprise and the main directions of digital technologies in them are briefly described.

\section{DISCUSSION}

Studies have shown that the use of digital technologies in logistics at many industrial enterprises in Russia is in its infancy, lags significantly behind industrialized countries, despite the fact that in society they pay a lot of attention. Automated production management systems are introduced in a few enterprises. At the same time, implementation issues are poorly addressed. The professional standards of logistics specialists poorly reflect the peculiarities of their functions, rights and obligations in the context of digital technologies.

\section{CONCLUSION}

The use of digital technologies, including logistics, is a global trend. Under these conditions, it is necessary to intensify theoretical work and implementation on them. Specialists in the field of economics, management and logistics should pay attention to changes in the management system of logistics activities: logistics business processes, infrastructure, functions of departments and employees, methods for evaluating and motivating them. 


\section{REFERENCES}

[1] Schwab K. The Fourth Industrial Revolution. Hardcover BUY. Jan 03, 2017. 192 p.J. Clerk Maxwell, A Treatise on Electricity and Magnetism, 3rd ed., vol. 2. Oxford: Clarendon, 1892, pp.68-73.

[2] Ismagilova, L.A., Gileva, T.A., Galimova, M.P., Glukhov, V.V. Digital business model and smart economy sectoral development trajectories substantiation (2017) 10531 LNCS, pp. 13-28.

[3] Zaychenko, I., Smirnova, A., Borremans, A. Digital transformation: The case of the application of drones in construction (2018) 193 05066.

[4] Boston Consulting Group (2017) Embracing Industry 4.0 - and Rediscovering Growth. URL: https://www.bcg.com/capabilities/operations/embracing-industry-4.0rediscovering-growth.aspx (04.06.2019).

[5] Bundesministerium fur Bildung und Forschung. Zukunftsbild "Industrie 4.0". URL: https://www. bmbf.de/pub/Zukunftsbild_Industrie_40.pdf, S. $6 \mathrm{f}$.

[6] McKinsey Global Institute (2015) Unlocking the potential of the Internet of Things. URL: https://www. mckinsey.com/businessfunctions/digital-mckinsey/our-insights/the-internet-of-things-the value-of-digitizing-the-physical-world (03.04.2018)

[7] Ilin, I.V., Iliashenko, O.Y., Klimin, A.I., Makov, K.M. Big data processing in Russian transport industry (2018) pp. 1967-1971.

[8] Zaychenko, I.M., Ilin, I.V., Lyovina, A.I. Enterprise architecture as a means of digital transformation of mining enterprises in the Arctic (2018) pp. 4652-4659.

[9] Ilin, I.V., Frolov, K.V., Lepekhin, A.A. From Business processes model of the company to software development: MDA business extension (2017) pp. 1157-1164.

[10] Cousins, P.D. and Spekman, R. Strategic supply and the management of inter- and intra-organizational relationships // Journal of Purchasing \& Supply Management, 2003, Vol. 9 No. 1, pp. 19-29.

[11] Optimal Coordinated Strategy Analysis for the Procurement Logistics of a Steel Group. Lianbo Deng, Zhuqiang Qiu, Pengfei Liu, and Wenzhong Xiao//Mathematical Problems in Engineering Volume 2014, Article ID 436512, 7 p.

[12] Chueva, T.I., Melnichuk, M.V., Ruchkina, G.F., Ilina, O.V., Litvinova, S.F. Foreign economic activity formation features in the regions of modern Russia (2017) 15 (23), pp. 245-254.

[13] Exploring the Effects of Centralised Procurement on Projects in South African Matrix Mining Organizations Mbali Milanzi1 *, Taryn BondBarnard//Project Management Institute Australia Conference 2017/

[14] Research on centralized purchasing management of China's chain retail enterprises Yan Wang, Xiaohan Gao//Proceedings of the 2018 International Conference on Economics, Business, Management and Corporate Social Responsibility (EBMCSR 2018).

[15] Katri Karjalainen. "Challenges of Purchasing Centralization Empirical Evidence from Public Procurement". Helsinki School of Economics, 2009

[16] Optimal Coordinated Strategy Analysis for the Procurement Logistics of a Steel Group. Lianbo Deng, Zhuqiang Qiu, Pengfei Liu, and Wenzhong Xiao//Mathematical Problemsin Engineering Volume, Article ID 436512, 7p., 2014

[17] Demidenko, D.S., Malevskaia-Malevich, E.D., Dubolazova, Y.A., Victorova, N.G. Optimization of the innovation process management at a manufacturing enterprise (2018) pp. 996-1003.

[18] Klimin, A.I., Pavlov, N.V., Efimov, A.M., Simakova, Z.L. Forecasting the development of big data technologies in the Russian Federation on the basis of expert assessments (2018) pp. 1669-1679.

[19] Short Papers, Workshops and Doctoral Consortium co-located with 17th International Conference Perspectives in Business Informatics Research (BIR 2018). Stockholm, Sweden, September 24-26, 2018.

[20] Data Science and Big Data. Python and the science of data / Davy Silen, Arnaud Meisman: 2017-336 c.

[21] Report McKinsey, 2011 - M.: McKinsey \& Company. 2011.

[22] Ilin, I., Iliashenko, O., Iliashenko, V. Approach to the choice of Big Data processing methods in financial sector companies (2018) MATEC Web of Conferences, 193, статья № 05061
[23] V. Dubolazov, A. Somov. Interval approach of time series forecasting by neural networks for the decision support system// MATEC Web of Conferences 170, 01014 (2018), 8 p.

[24] Levina, A.I., Dubgorn, A.S., Iliashenko, O.Y. Internet of things within the service architecture of intelligent transport systems (2018) Proceedings - 2017 European Conference on Electrical Engineering and Computer Science, EECS 2017, pp. 351-355. 